\title{
HIGHLY COMPENSATED GaAs CRYSTAL OBTAINED BY MOLECULAR CO DOPING
}

\author{
R. Bożek, K.P. Korona, G. Nowak, D. Wasik, T. Slupiński \\ Institute of Experimental Physics, Warsaw University \\ Hoża 69, 00-681 Warszawa, Poland \\ AND P. KACZOR \\ Institute of Physics, Polish Academy of Sciences \\ Al. Lotników 32/46, 02-668 Warszawa, Poland
}

\begin{abstract}
GaAs:C crystal was grown by liquid encapsulated Czochralski technique with large partial pressure of $\mathrm{CO}$ in ambient atmosphere $p_{\mathrm{Co}} / p_{\mathrm{tot}}=0.2$ and investigated using near and infrared absorption, photoluminescence, photoconductivity, photo-induced current transient spectroscopy and photo-Hall measurements. High resistivity of the crystal was found in electrical measurements $\left(10^{7} \Omega \mathrm{cm}\right.$, the Fermi level at $0.67 \mathrm{eV}$ below conduction band at $\left.300 \mathrm{~K}\right)$. Local vibrational mode revealed increased concentration of carbon acceptor and presence of oxygen related complexes. Photoluminescence spectra were dominated by two bands with peak energies at $1.49 \mathrm{eV}$ and $0.8 \mathrm{eV}$. The near band gap emission shifts with excitation intensity up to $4 \mathrm{meV} /$ decade. In photocurrent spectrum a strong photoionization band with $E=0.55 \mathrm{eV}$ is observed.
\end{abstract}

PACS numbers: 71.55. $-\mathrm{i}, 78.55 .-\mathrm{m}, 78.20 . \mathrm{Jq}$

Carbon incorporation into liquid encapsulated Czochralski (LEC) GaAs is carefully studied because of its important role together with EL2 in compensation mechanism leading to semi-insulating (SI) GaAs. It was established [1, 2] that carbon concentration may be controlled by partial pressure of $\mathrm{CO}$ in the ambient gas during crystal growth. In those experiments $\mathrm{CO}$ pressure was kept below $0.5 \%$. Our intention was to obtain crystal with high concentration of carbon acceptors by increase in $\mathrm{CO}$ pressure.

In our experiment GaAs was synthesised in situ. The crystal was grown using standard LEC technique except that after melting the material the $\mathrm{CO}_{2}$ gas at $1 \mathrm{~atm}$ was injected into the chamber filled with $\mathrm{N}_{2}$ gas under pressure of $8 \mathrm{~atm}$. This resulted in $2 \mathrm{~atm}$ of $\mathrm{CO}$ over growing crystal due to the reaction of oxygen from thermally dissociated $\mathrm{CO}_{2}$ particles with graphite heaters.

Far infrared absorption was measured at $11 \mathrm{~K}$ using Bomem DA3 FTIR spectrometer. Five sharp absorption lines were observed at 582,1162, 1244, 1285, and $1325 \mathrm{~cm}^{-1}$. The first line $\left(582 \mathrm{~cm}^{-1}\right)$ corresponds to local vibrational mode (LVM) 
of isolated carbon acceptor $\mathrm{C}_{\mathrm{As}}[3,4]$. Using calibration factor $f=$ $8 \times 10^{15} \mathrm{~cm}^{-3}$ [5], we found carbon concentration equal to $1.1 \times 10^{16} \mathrm{~cm}^{-3}$ with $10 \%$ tolerance. For comparison, carbon concentration in several other SI GaAs grown by LEC method without the CO injection did not exceed $7 \times 10^{14} \mathrm{~cm}^{-3}$. The rest of far infrared absorption lines were due to LVM of oxygen related complexes [6]. Their overall concentration was typical of GaAs crystals grown by LEC technique.

The near infrared absorption measurements were performed at helium temperature using Cary 5 spectrophotometer. EL2 concentration was determined as equal to $2 \times 10^{16} \mathrm{~cm}^{-3}$. The value of the Hall mobility measured at $250 \mathrm{~K}$ was low (below $100 \mathrm{~cm}^{2} / \mathrm{Vs}$ ) but it increased after illumination, which suggested that electrical transport in this crystal was dominated by conductivity via impurity band. Thermal activation energy of the hopping conductivity was found to be: $\varepsilon_{3}=0.12 \mathrm{eV}$. It indicates that electric potentials with amplitude of the order of $0.2 \mathrm{eV}$ exist in the sample.

Photocurrent measurements at room temperature and at $14 \mathrm{~K}$ were done (see Fig. 1). At room temperature the spectrum was dominated by a strong band

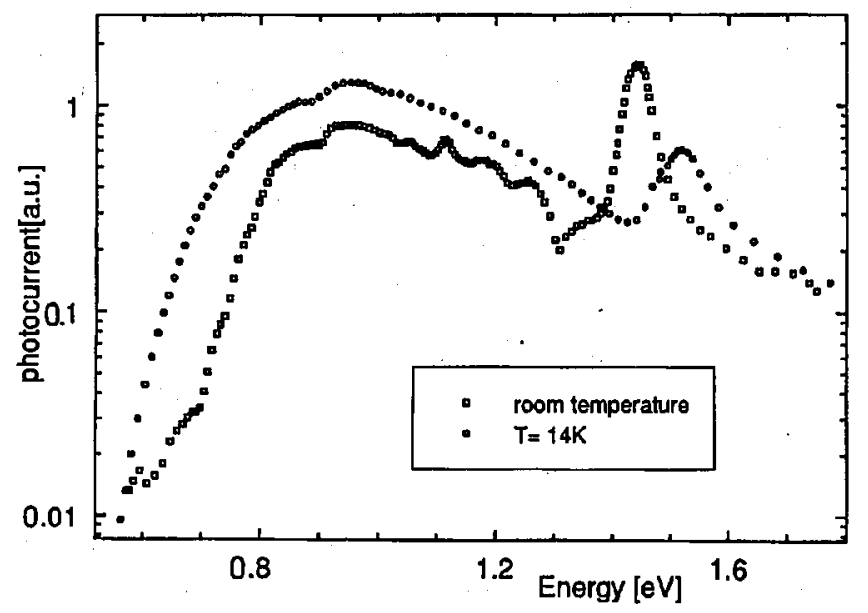

Fig. 1. Photocurrent spectra measured at room temperature and at $14 \mathrm{~K}$ (after. EL2 quenching to metastable state).

between 0.6 and $1.3 \mathrm{eV}$. At $14 \mathrm{~K}$ photocurrent value was significantly smaller. Therefore, it was possible to observe the $\mathrm{EL} 2^{0+}+h \nu \rightarrow \mathrm{EL}^{2+}+\mathrm{e}_{\mathrm{CB}}$ photoionization band [7]. The lower energy band observed at room temperature was present but with smaller amplitude. Its ionization energy was found to be equal to $0.55 \mathrm{eV}$. Current versus time dependence, measured during EL2 photoquenching, reached minimum after $50 \mathrm{~s}$ and then increased to the value much higher than the initial photocurrent which is characteristic of samples with high carbon concentration [8]. It was shown [9] that during such photoquenching sample was transformed to $p$ type. Photocurrent spectrum measured after EL2 transition to the metastable 
state consisted only of the $0.55 \mathrm{eV}$ photoionization band (Fig. 1). This band could be connected with an ionization of some oxygen-related defects or with EL2 ${ }^{++}+$ $h \nu \rightarrow \mathrm{EL} 2^{+}+\mathrm{h}_{\mathrm{VB}}$ transition. The second possibility would mean coexistence of $\mathrm{EL} 2^{\circ}$ and EL2 ${ }^{++}$states in the sample at $14 \mathrm{~K}$. It can be explained by potential fluctuations with amplitude of at least $E_{\mathrm{EL} 20 /+}-E_{\mathrm{EL} 2+/++}=0.27 \mathrm{eV}$. Thermally stimulated current and photo-induced current transient spectroscopy (PICTS) was measured. Carriers were excited with $h \nu=1.3 \mathrm{eV}$ light. At $22 \mathrm{~K}$ very strong peak related to $\mathrm{C}_{\mathrm{As}}$ acceptor was observed. In the temperature range of $160-250 \mathrm{~K}$ two peaks were observed. These were EL4 and EL5 traps frequently observed in GaAs and related to $\mathrm{V}_{\mathrm{As}}$ and $\mathrm{V}_{\mathrm{As}}-\mathrm{O}$ deep donors [10]. Photoluminescence (PL) measured at $4.2 \mathrm{~K}$ was excited with $780 \mathrm{~nm}$ laser diode. Excitation intensity was varied from 0.0005 to $5 \mathrm{~W} / \mathrm{cm}^{2}$. PL was analysed using SPEX 500M monochromator with cooled S20 PMT or Ge diode.

The PL spectrum was dominated by two bands with peak energies at $1.49 \mathrm{eV}$ and $0.8 \mathrm{eV}$ (Fig. 2). The near band gap emission (donor-acceptor, D-A) demon-

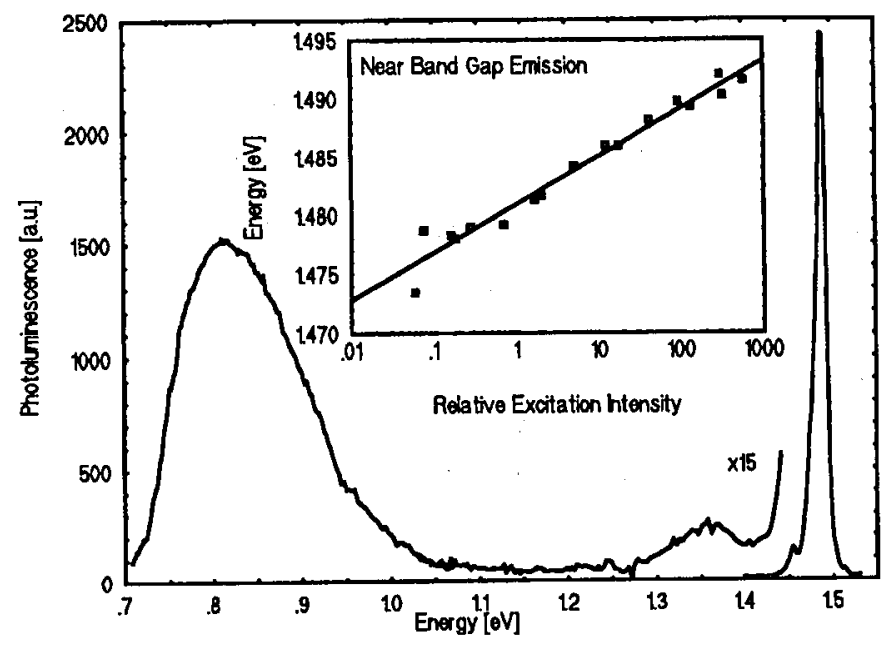

Fig. 2. Photoluminescence spectrum measured at $4.2 \mathrm{~K}$. Insert shows the relation between peak energy of near band gap emission and excitation intensity.

strated strong dependence on excitation intensity which is not common in LEC SI GaAs. This dependence is described by the equation

$$
E=E_{0}+\alpha \log \left(I / I_{0}\right)
$$

in the whole range of excitation intensity. The coefficient $\alpha$ was found to vary from 2 to $4 \mathrm{meV} /$ decade for different samples measured. Such a behaviour reported earlier in Cr-doped SI GaAs and second group acceptors implanted layers [11] may be explained in terms of influence of the Coulomb potential fluctuations on the shape of valence and conduction bands. It proves abundance of charged centres or their associates in the crystal and a large value of the screening radius. 
PL emission with peak at $0.8 \mathrm{eV}$ is common to many LEC SI GaAs crystals but the consensus about the unique interpretation was not achieved. It was proposed [12] that it may be related to the transition from the conduction band to the doubly ionized state of $\mathrm{As}_{\mathrm{Ga}}^{++}\left(\mathrm{EL}^{++}\right)$donor. This would agree with the photocurrent results.

In conclusion, we obtained a semi-insulating GaAs crystal containing both $\mathrm{C}_{\mathrm{As}}$ acceptors and oxygen related complexes. It was found that the concentration of $\mathrm{C}_{\mathrm{As}}$ acceptors was large enough to ionize EL2 and oxygen related donors.

The work was financially supported by the Committee for Scientific Research grant number 204249101.

\section{References}

[1] P.J. Doering, B. Freidenreich, R.J. Tobin, P.J. Pearah, J.P. Tower, R.M.Ware, in: Semi-insulating III-V Materials, Toronto 1990, Eds. A. Milnes, C.J. Miner, Adam Hilger, Bristol 1990, p. 173.

[2] N. Sato, M. Kakimoto, Y. Kadota, in Ref. [1], p. 211.

[3] R.C. Newman, F. Thompson, M. Hyliands, R.F. Peart, Solid State Commun. 10, 505 (1972).

[4] W.M. Theis, K.K. Bajaj, C.W. Litton, W.G. Spitzer, Appl. Phys. Lett. 41, 70 (1982).

[5] M.R. Brozel, in: Semi-insulating III-V Materials, Hakone 1986, Eds. H. Kukimoto, S. Miyazawa, North-Holland, Amsterdam 1986, p. 217.

[6] M. Skowroński, R.E. Kremer, J. Appl. Phys. 69, 7825 (1991).

[7] D. Bois, A. Chantre, Rev. Phys. Appl. F 15, 631 (1980).

[8] M.O. Manasreh, W.C. Mitchel, D.W. Fischer, Semicond. Sci. Technol. 5, 994 (1990).

[9] R.P. Kiliulis, Ph.D. Thesis.

[10] Z.-Q. Fang, D.C. Look, J. Appl. Phys. 69, 8177 (1991).

[11] Phil Won Yu, J. Appl. Phys. 48, 5043 (1977).

[12] Phil Won Yu, Phys. Rev. B 29, 2283 (1984). 